\title{
Thermal Analysis on Mono-Block Type Divertor Based on Subcooled Flow Boiling Critical Heat Flux Data against Inlet Subcooling in Short Vertical Tube
}

\author{
Koichi HATA, Masahiro SHIOTSU ${ }^{1)}$ and Nobuaki NODA ${ }^{2)}$ \\ Institute of Advanced Energy, Kyoto University, Uji 611-0011, Japan \\ ${ }^{1)}$ Deptartment of Energy Science and Technology, Kyoto University, Uji 611-0011, Japan \\ ${ }^{2)}$ National Institute for Fusion Science, Toki 509-5292, Japan
}

(Received 8 December 2005 / Accepted 14 February 2006)

\begin{abstract}
The subcooled flow boiling critical heat fluxes (CHFs) and the heat transfer coefficients (HTCs) data for the tube length, $L$, of 49, 99 and $149 \mathrm{~mm}$ with 9-mm inner diameter were applied to thermal analysis on the Mono-block type divertor of LHD. Incident CHFs for the divertor with the cooling tube diameter, $d$, of $10 \mathrm{~mm}$ and the carbon armor outer diameter, $D$, of 26 and $33 \mathrm{~mm}$ were numerically analyzed based on the measured CHFs and HTCs at the inlet pressure of around $800 \mathrm{kPa}$. The numerical solutions were also compared with those for the Flat-plate type divertor, which were numerically analyzed for the divertor with the cooling tube diameter $d=10 \mathrm{~mm}$ and the divertor width, $w$, ranging from 16 to $30 \mathrm{~mm}$. It is confirmed that the ratio of the one-side heating CHF data, $q_{\mathrm{cr}, \text { inc }}$, to the uniform heating $\mathrm{CHF}$ data, $q_{\mathrm{cr}, \text { sub }}$, can be represented as the simple equation based on the numerical solutions. The values of the $q_{\mathrm{cr} \text {,inc }}$ for $L=50,100$ and $150 \mathrm{~mm}$ were estimated with various $D / d$ and $w / d$ at higher pressures.
\end{abstract}

(C) 2006 The Japan Society of Plasma Science and Nuclear Fusion Research

Keywords: subcooled flow boiling critical heat flux, incident critical heat flux, mono-block type divertor, numerical solution

DOI: $10.1585 /$ pfr.1.017

\section{Introduction}

The understanding of the critical heat flux (CHF) on vertical tube inner surface in subcooled water flowing upward is important as a database for the design of a divertor plate in a nuclear fusion facility.

Various studies have been conducted on the CHF in water for high heat flux heat removal. For example, the experimental investigation for CHF on tubes with and without a twisted tape or a coiled wire has been presented. Heat transfer coefficient and critical heat flux for water in swirl flow through tubes with internal twisted tapes was conducted by Gambill et al. [1]. The correlation of the non-boiling heat transfer coefficient was presented and it was demonstrated that CHF with swirl flow was twice as large as with straight flow through an identical tube without a twisted tape. The swirl tube with the effect of twophase heat transfer and asymmetric heating of tubular elements was numerically analyzed to study the performance of swirl-flow-based neutral particle beam targets by Milora et al. [2]. CHF of subcooled flow boiling with water in tubes under peripherally non-uniform heating conditions was investigated by Nariai and Inasaka [3]. Divavin et al. [4] carried out the high heat flux experiments on rectangular samples with cylindrical cooling ducts with one-side heating to the effect of a porous coating deposed on inner

author'se-mail: hata@iae.kyoto-u.ac.jp cooled surface on the Incident Critical Heat Flux (ICHF) performance at water subcooled boiling regime. They defined the empirical correlation between ICHF at one-side heating condition and geometrical parameters of elements of cooling design. The critical heat flux (CHF) experiments for the different geometries (smooth tube, finned swirl tube, screw tube and hypervapotron) were performed in the thermal hydraulic conditions of fusion reactors: oneside heating, high heat flux and water-cooled by JAERI (Japan Atomic Energy Research Institute) [5]. Recently, three-dimensional thermal measurements for a one-sideheated mono-block were made for the robust design of one-side-heated plasma-facing components and other high heat flux components by Boyd et al. [6].

The heat load tests have been under way by the electron beam heating on a divertor element which consists of the carbon armors joined to the copper heat-sink with a cooling tube. A helical type fusion experimental device which is Large Helical Device (LHD) located in the National Institute for Fusion Science, Japan, has two types of divertor element. One is Mono-block type (Cylindrical one), the other is Flat-plate type (Rectangular one). Figure 1 shows a typical photograph of the LHD divertor, Mono-block type. It is important to clarify the relation between the uniform heating CHF data, $q_{\mathrm{cr}, \mathrm{sub}}$, on the test tube heated by a steadily increasing current and the 


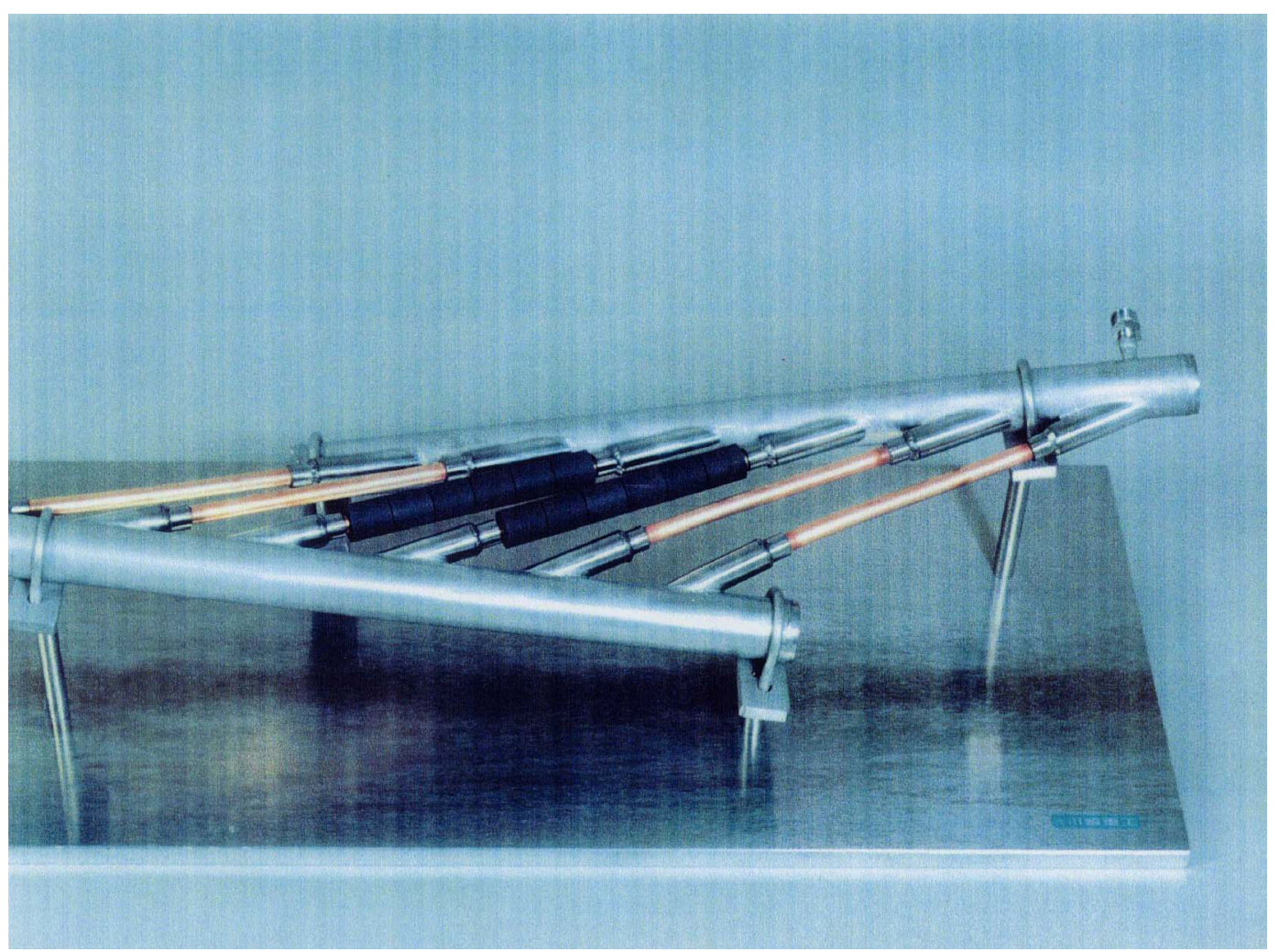

Fig. 1 Typical photograph of the LHD divertor, Mono-block type.

one-side heating CHF data, $q_{\mathrm{cr} \text {,inc }}$, on the divertor element heated by an electron beam facility with the effect of the cooling tube length.

The purpose of this study is first to make the thermal analysis of the Mono-block type divertor based on the CHFs and the HTCs data for the tube length, $L$, of 49,99 and $149 \mathrm{~mm}$ with $9-\mathrm{mm}$ inner diameter, and secondly to give the ratio of the $q_{\mathrm{cr} \text {,inc }}$ to the $q_{\mathrm{cr}, \mathrm{sub}}$ and establish the database for the high heat flux thermal management at the divertor.

\section{Divertor Types}

The cross-sectional views of Mono-block type divertor and Flat-plate type are shown in Figs. 2 (a) and (b), respectively. The Mono-block type divertor is made of the oxygen-free copper cooling tube with $10 \mathrm{~mm}$ inner diameter and $1.5 \mathrm{~mm}$ thickness, and the carbon armor (CX2002U) with $33 \mathrm{~mm}$ outer diameter and $10 \mathrm{~mm}$ thickness. The cooling tube is located in the center of the carbon armor. The carbon armor is brazed to the cooling tube. On the other hand, the Flat-plate type one is made of the oxygen-free copper block of $30 \mathrm{~mm}$ wide by $25 \mathrm{~mm}$ high and the carbon tile (CX2002U) of $30 \mathrm{~mm}$ wide by $10 \mathrm{~mm}$ high. The carbon tile is brazed to the copper block. The cooling tube with the inner diameter of $10 \mathrm{~mm}$ is horizontally located at the height of $17 \mathrm{~mm}$ from the lower surface on the central line of the copper block. The heated lengths of the divertors are given as 49,99 and $149 \mathrm{~mm}$ in this

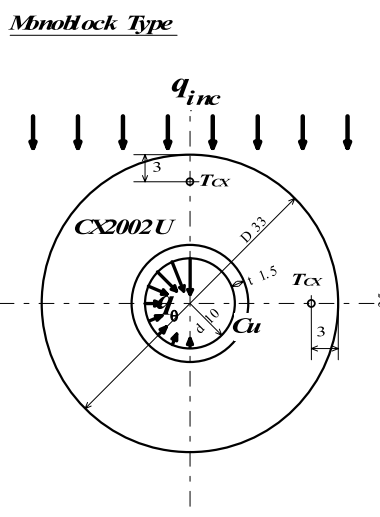

Hat-Hate Type

(a)

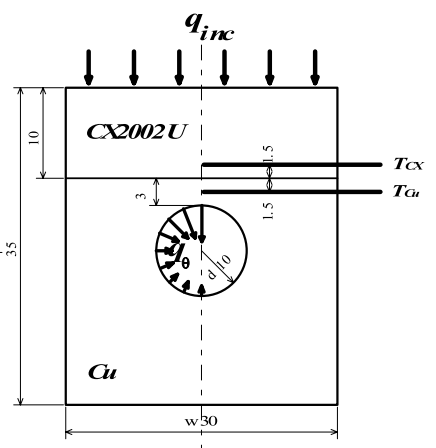

(b)

Fig. 2 Cross-sectional views of LHD divertors, (a) Mono-block type and (b) Flat-plate type.

work, which are equal to the heated lengths of the test tubes in the former CHF experiments [7-16]. The high heat flux heat removal is achieved by the following way; the heat induced by collecting the high heat flux flow and the high energy particles on the carbon armor upper surface is transferred to the highly subcooled and pressurized water due to the forced convection and nucleate boiling heat transfer on the inner surface of the cooling tube. It was supposed that the lower surface for the Mono-block type diverter and the 
right, left and lower surfaces for the Flat-plate type one are under the adiabatic conditions because the divertor is equipped in the plasma vessel which will be normally operated under ultra-high vacuum $\left(10^{-5} \mathrm{~Pa}\right.$ for hydrogen $)$.

\section{Numerical Analysis of the Mono- Block Type Divertor}

\subsection{Fundamental equations}

The unsteady two-dimensional heat conduction equation for the Mono-block type divertor in the coordinate system shown in Fig. 3 is described as follows. The Flat-plate type one is shown in Appendix.

$$
\begin{aligned}
& \frac{\partial}{\partial t}(\rho c T)=\frac{1}{r} \frac{\partial}{\partial r}\left(r \lambda \frac{\partial T}{\partial r}\right)+\frac{1}{r} \frac{\partial}{\partial \theta}\left(\frac{\lambda}{r} \frac{\partial T}{\partial \theta}\right) \\
& \text { for } d / 2 \leq r \leq D / 2 \text { and } 0 \leq \theta \leq \pi,
\end{aligned}
$$

where $\rho, c$ and $\lambda$ are density $\left(\mathrm{kg} / \mathrm{m}^{3}\right)$, specific heat $(\mathrm{J} / \mathrm{kg}$ $\mathrm{K})$ and thermal conductivity $(\mathrm{W} / \mathrm{mK})$, respectively and the carbon armor outer diameter, $D$, and the cooling tube diameter, $d$, are in (m). The $z$-direction thickness of the control volume is assumed to be unity. The numerical analysis is performed within $0 \leq \theta \leq \pi$ as the symmetrical problem. The boundary conditions are expressed in the following forms.

$$
\begin{aligned}
& \frac{\partial T}{\partial r}=0 \quad \text { at } r=D / 2 \text { for } 0 \leq \theta \leq \pi / 2, \\
& \left(q_{\text {wall }}\right)_{i}=q_{\text {inc }} \frac{18}{\pi}\left\{\sin \frac{\pi}{18} i-\sin \frac{\pi}{18}(i-1)\right\} \\
& \text { at } r=D / 2 \text { for } \pi(i-1) / 18 \leq \theta \leq \pi i / 18(i=10 \text { to } 18),
\end{aligned}
$$

$$
q=-q_{\theta} \quad \text { at } r=d / 2,
$$

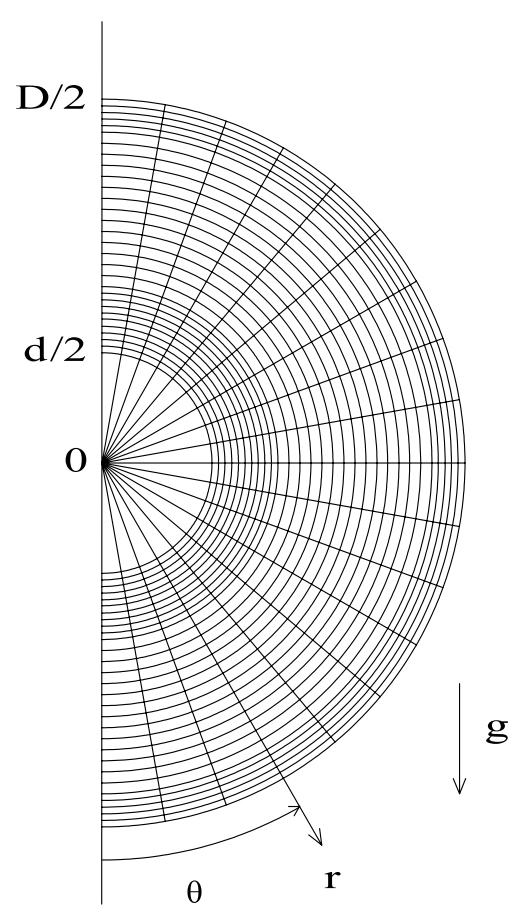

Fig. 3 Coordinates of Mono-block type divertor. where the outer surface heat flux of carbon armor, $\left(q_{\text {wall }}\right)_{i}$, and the inner surface heat flux of the cooling tube, $q_{\theta}$, are in $\left(\mathrm{W} / \mathrm{m}^{2}\right)$. The $\left(q_{\text {wall }}\right)_{i}$ are given as the values calculated from the incident heat flux, $q_{\text {inc }}$, at every $\pi / 18$ for $\theta$ ranging from $\pi / 2$ to $\pi$. The $q_{\theta}$ are given with the aid of the relation between the heat flux, $q$, and the surface temperature, $T_{\mathrm{s}}$, previously obtained based on the surface temperature of the cooling tube numerically analyzed at every $\pi / 18$ for $\theta$ ranging from 0 to $\pi$.

\subsection{Calculation method}

Boiling curves measured by three different heated lengths of the test tubes under the same experimental condition (pressure at inlet of heated section, $P_{\text {in }}$, in $(\mathrm{kPa})$, flow velocity, $u$, in $(\mathrm{m} / \mathrm{s})$ and inlet liquid temperature, $T_{\text {in }}$, in $(\mathrm{K})=$ constant) are used for the numerical analysis. Figure 4 shows the heat transfer characteristics for $d=9 \mathrm{~mm}$ tube with $L=149 \mathrm{~mm}$ for the inlet condition of $P_{\text {in }}=775 \mathrm{kPa}, u=9.9 \mathrm{~m} / \mathrm{s}$ and $T_{\text {in }}=306.76 \mathrm{~K}$ as a typical example. The heat flux gradually becomes higher with an increase in $\left(T_{\mathrm{s}}-T_{\text {in }}\right)$ on the forced convection heat transfer derived from Nusselt correlation [17] up to the point where the slope begins to increase with heat flux following the onset of nucleate boiling, and increases up to a value called CHF where the heater surface temperature rapidly jumps from the nucleate boiling heat transfer regime $(\mathrm{N}-$ B) to the film boiling one (F-B). The film boiling curve in the figure is given by the values derived from Shiotsu and Hama's correlation $[18,19]$. It is assumed that the film boiling exists for the heater surface temperature, $T_{\mathrm{s}}$, higher than the homogeneous spontaneous nucleation temperature, $T_{\mathrm{H}}$. The transition boiling curve is given as the straight line drawn between the point for $\left(T_{\mathrm{s}}-T_{\text {in }}\right) 20 \mathrm{~K}$ higher than that at CHF and that at the minimum heat flux. The plateau was adopted based on the experimental study

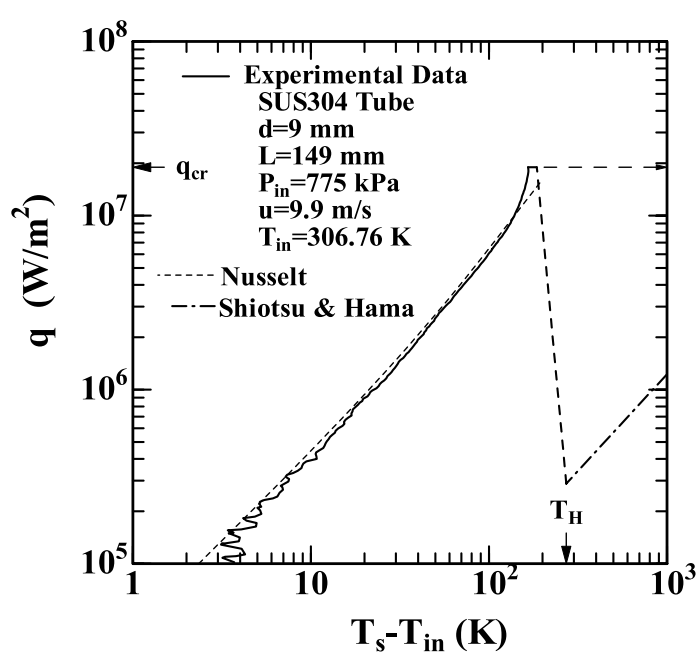

Fig. 4 Relationship between $q$ and $\left(T_{\mathrm{s}}-T_{\text {in }}\right)$ with $L=149 \mathrm{~mm}$ at an inlet pressure of $775 \mathrm{kPa}$. 
on transient boiling heat transfer including transition to film boiling on a heated horizontal cylinder in a pool of water caused by a rapid pressure reduction from an initial pressure [20,21]. Minimum film boiling temperature or heat flux on inner surface of a vertical tube with water flowing upward is neither clearly understood at present experimentally nor theoretically. On the other hand, Sakurai et al. [22] performed systematic experiments of minimum film boiling states on horizontal cylinders in a pool of liquids at various pressures. They observed that the minimum film boiling temperature, $T_{\min }$, in each liquid was lower than the homogeneous spontaneous nucleation temperature, $T_{\mathrm{H}}$, at atmospheric pressure, and it increased and approached $T_{\mathrm{H}}$ with the increase in the pressure. In case of water, $T_{\min }$ almost agreed with $T_{\mathrm{H}}$ for the pressures higher than around $1 \mathrm{MPa}$. They also reported that the minimum film boiling state seemed to be characterized by the surface temperature rather than the heat flux. It was because $T_{\min }$ on different diameter cylinders under the same condition agreed with each other, although the heat flux at the point was lower for larger diameter cylinder due to the dependence of film boiling heat transfer coefficients on cylinder diameter. It is assumed based on these facts that $T_{\min }$ for the forced convection film boiling of water at high pressures would be around $T_{\mathrm{H}}$.

The $q_{\theta}$ value for each control volume is given from the boiling curve shown in Fig. 4 as the heat flux at the surface temperature numerically obtained for each control volume. The boiling curve shown in Fig. 4 was formulated to give the surface heat flux on the cooling tube in the CFD (Computational Fluid Dynamics) code as follows:

$$
\begin{aligned}
& q=C \Delta T^{n}, \\
& \Delta T=T_{\mathrm{s}}-T_{\mathrm{in}},
\end{aligned}
$$

where all constants, $C$ and $n$, are given in Table 1 . The surface heat flux, $q_{\theta}$, and the surface temperature, $T_{\mathrm{s}}$, on

\begin{tabular}{|c|c|c|c|c|c|}
\hline $\begin{array}{c}P_{\text {in }} \\
(\mathrm{kPa})\end{array}$ & $\begin{array}{c}L \\
(\mathrm{~mm})\end{array}$ & $\begin{array}{c}\text { Boiling } \\
\text { Condition } \\
\end{array}$ & $C$ & $n$ & $\begin{array}{c}\left(T_{\mathrm{s}}-T_{\text {in }}\right) \text { Range } \\
(\mathrm{K})\end{array}$ \\
\hline \multirow{7}{*}{775} & \multirow{7}{*}{149} & $\begin{array}{l}\text { Forced } \\
\text { Convection }\end{array}$ & $1.7152 \times 10^{4}$ & 1.2755 & $\begin{array}{ll}0 & \text { to } \\
129.767\end{array}$ \\
\hline & & \multirow{4}{*}{$\begin{array}{l}\text { Nucleate } \\
\text { Boiling }\end{array}$} & 88.259 & 2.3585 & $\begin{array}{ll}129.767 & \text { to } \\
148.341 & \end{array}$ \\
\hline & & & 1.912 & 3.125 & $\begin{array}{ll}148.341 & \text { to } \\
163.146 & \\
\end{array}$ \\
\hline & & & $3.4559 \times 10^{-21}$ & 12.5 & $\begin{array}{ll}163.146 \\
165.622\end{array}$ \\
\hline & & & $18.947 \times 10^{6}$ & 0 & $\begin{array}{ll}165.622 \\
185.622\end{array}$ \\
\hline & & $\begin{array}{l}\text { Transition } \\
\text { Boiling }\end{array}$ & $1.4225 \times 10^{32}$ & -10.965 & $\begin{array}{l}185.622 \\
271.89\end{array}$ \\
\hline & & $\begin{array}{l}\text { Film } \\
\text { Boiling }\end{array}$ & 568.95 & 1.1111 & $\begin{array}{l}\text { Higher than } \\
271.89\end{array}$ \\
\hline
\end{tabular}

Table 1 Constants of Eq. (5) the cooling tube was calculated from the analyzed temperature, $T_{1}$, at the central point of the first control volume on the cooling tube, by the 50-times iteration on the thermal conduction in the control volume as follows:

$$
\begin{aligned}
& \lambda_{\mathrm{cu}}\left(T_{1}\right)=f\left(T_{1}\right) \\
& q_{\mathrm{s} 1}=C\left(T_{1}-T_{\mathrm{in}}\right)^{n} \\
& T_{s}=T_{1}-q_{\mathrm{s} 1} \frac{\ln (1+\Delta r / d)}{2 \pi \lambda_{\mathrm{cu}}\left(T_{1}\right)} \\
& q_{\mathrm{s}}=C\left(T_{\mathrm{s}}-T_{\mathrm{in}}\right)^{n} \\
& T_{s}=T_{1}-q_{s} \frac{\ln (1+\Delta r / d)}{2 \pi \lambda_{\mathrm{cu}}\left(T_{1}\right)} \\
& q_{\theta}=q_{\mathrm{s}}
\end{aligned}
$$

where the thermal conductivity of the oxygen-free copper, $\lambda_{\mathrm{cu}}$ is in $(\mathrm{W} / \mathrm{mK})$ and the depth of the first control volume on the cooling tube, $\Delta r$, is in (m). Equations (10) and (11) were iterated 50 times in the code. All the calculations were made by using the PHOENICS code [23].

\section{Results and Discussion \\ 4.1 Conditions for calculation}

The heat characteristic of Mono-block type divertors are numerically analyzed under the following conditions:

Mono-block Type Divertors

Material : Oxygen free copper tube and cylindrical CX2002U

Outer diameter $(D)$ :

Heated Length $(L)$ :

Incident Heat Flux $\left(q_{\text {inc }}\right)$ :

26 and $33 \mathrm{~mm}$

Cooling Tube Diameter $(d)$ :

49, 99 and $149 \mathrm{~mm}$

$11-16 \mathrm{MW} / \mathrm{m}^{2}$

$10 \mathrm{~mm}$

$\begin{array}{ll}\text { Cooling Water } & \\ \text { Inlet Pressure }\left(P_{\text {in }}\right): & 775-792 \mathrm{kPa} \\ \text { Flow Velocity }(u): & 9.9 \mathrm{~m} / \mathrm{s} \\ \text { Inlet Liquid Temperature }\left(T_{\text {in }}\right): & 306.76-308.65 \mathrm{~K} \\ & \left(33.61-35.5^{\circ} \mathrm{C}\right)\end{array}$

\subsection{Incident critical heat flux}

Figure 5 shows the numerically obtained time variations in the surface temperature of the carbon armor on the central line of the divertor, $T_{\text {wall }}$, the inner temperature of the carbon armor, $T_{\mathrm{cx}}$, the outer temperature of the copper cooling tube, $T_{\mathrm{cu}}$, and the inner surface temperature of the copper cooling tube, $T_{\mathrm{s}}$, for $q_{\mathrm{inc}}=11 \mathrm{MW} / \mathrm{m}^{2}$ for the carbon armor outer diameter, $D$, of $33 \mathrm{~mm}$ with the cooling tube diameter, $d$, of $10 \mathrm{~mm}$, which is cooled with highly subcooled and pressurized water for the inlet liquid temperature, $T_{\text {in }}$, of $306.76 \mathrm{~K}$ at the inlet pressure, $P_{\text {in }}$, of $775 \mathrm{kPa}$ with the flow velocity, $u$, of $9.9 \mathrm{~m} / \mathrm{s}$. The surface temperature of the carbon armor (CX2002U) rapidly increases up to $1199 \mathrm{~K}$ within 5 seconds of the heating and gradually approaches the constant value of about $1218 \mathrm{~K}$ with the elapse of time.

The peripheral distributions of the surface heat flux, $q_{\theta}$, and the inner surface temperature, $T_{\mathrm{s}}$, on the cooling tube and the intersectional one of $T_{\text {wall }}$ on the carbon sur- 


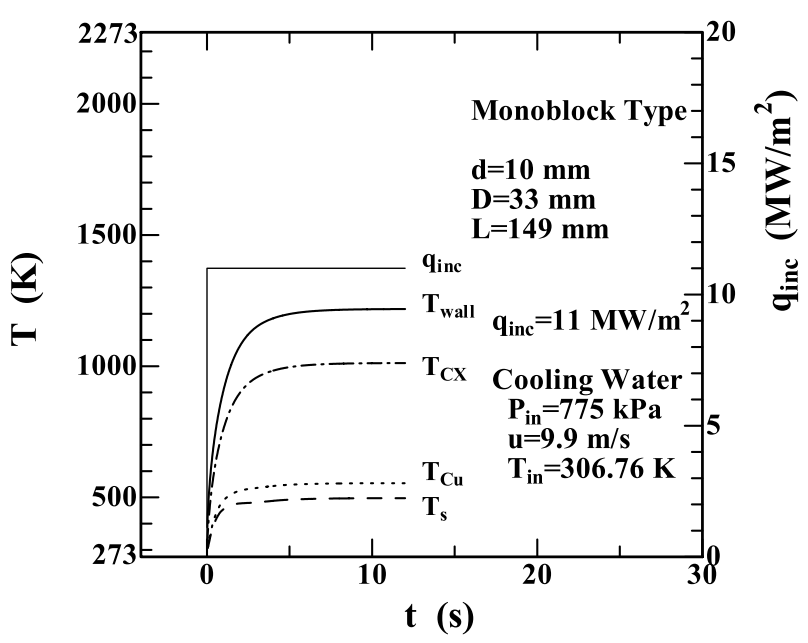

Fig. 5 Time variations in $T_{\text {wall }}, \quad T_{\mathrm{CX}}, \quad T_{\mathrm{Cu}}$ and $T_{\mathrm{s}}$ for $q_{\text {inc }}=11 \mathrm{MW} / \mathrm{m}^{2}$ with $L=149 \mathrm{~mm}$.

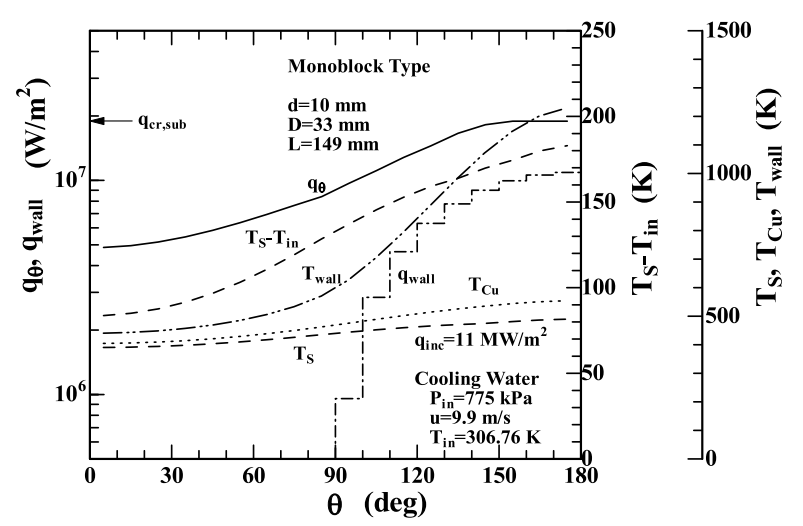

Fig. 6 Peripheral distribution of $q_{\text {wall }}, q_{\theta}, T_{\mathrm{s}}, T_{\mathrm{Cu}}, T_{\mathrm{s}}-T_{\text {in }}$ and $T_{\text {wall }}$ for $q_{\mathrm{inc}}=11 \mathrm{MW} / \mathrm{m}^{2}$.

face after 12 seconds of the heating are shown in Fig. 6 with the experimental data point of $\mathrm{CHF}, q_{\mathrm{cr}, \mathrm{sub}}$. The line, $\theta=0^{\circ}$, is the central axis of the carbon armor. The $q_{\theta}$ values on the cooling tube are widely distributed ranging from $4.86 \mathrm{MW} / \mathrm{m}^{2}$ at $\theta=0^{\circ}$ (the bottom of the cooling tube) to $18.95 \mathrm{MW} / \mathrm{m}^{2}$ at $\theta=180^{\circ}$ (the top of the one) which is almost the CHF value. It is assumed the vapor behavior on the cooling tube surface from this figure that the heat transfer on the inner surface of the cooling tube for $q_{\text {inc }}=11 \mathrm{MW} / \mathrm{m}^{2}$ will be in non-boiling forced convection for the lower part of the tube and in nucleate boiling (N-B) for the upper part of the tube.

The numerical solutions of the time variations in $T_{\text {wall }}$, $T_{\mathrm{cx}}, T_{\mathrm{cu}}$ and $T_{\mathrm{s}}$ for $q_{\mathrm{inc}}=12 \mathrm{MW} / \mathrm{m}^{2}$ are shown in Fig. 7 . After 3.4 seconds of the heating, the $T_{\text {wall }}$ value steeply increases again because the top inner surface of the cooling tube begins to be covered with vapor, the vapor spreads downward the cooling tube surface and the surface temperature of the cooling tube jumps to that of the film boiling regime $(\mathrm{F}-\mathrm{B})$. The incident critical heat flux, $q_{\mathrm{cr}, \text { inc }}$, is

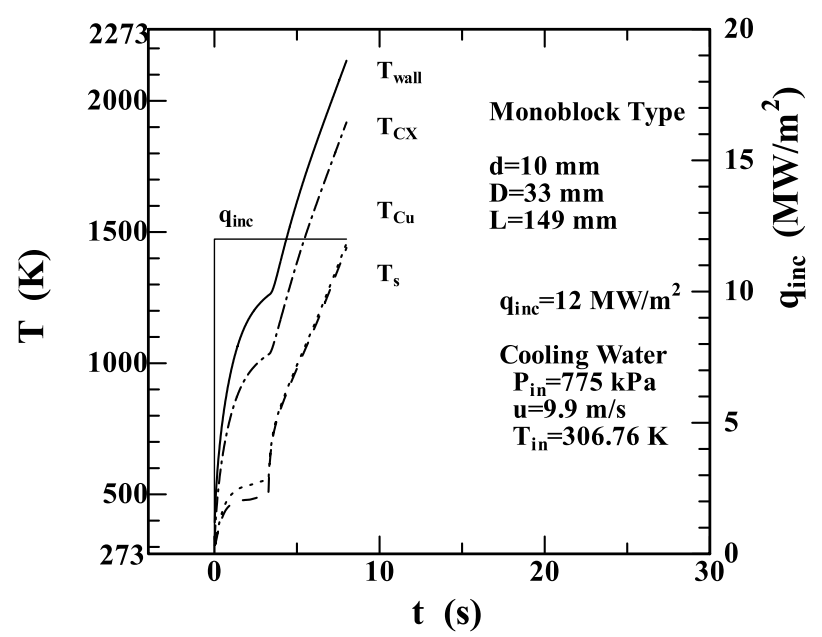

Fig. 7 Time variations in $T_{\text {wall }}, \quad T_{\mathrm{CX}}, \quad T_{\mathrm{Cu}}$ and $T_{\mathrm{s}}$ for $q_{\text {inc }}=12 \mathrm{MW} / \mathrm{m}^{2}$ with $L=149 \mathrm{~mm}$.

defined as the maximum value of $q_{\text {inc }}$ without the steep increase of $T_{\text {wall }}$ due to the surface temperature on the cooling tube increasing to that of the film boiling regime (F-B).

The contours of the cross-section temperature of the divertor which were numerically solved at 12 and $8 \mathrm{sec}-$ onds after the heating for $q_{\text {inc }}$ of 11 and $12 \mathrm{MW} / \mathrm{m}^{2}$ are shown on Fig. 8. The phenomena on the inner surface of the cooling tube are observed to be in the non-boiling forced convection and nucleate boiling regimes (N-B), and the film boiling regime (F-B), respectively.

\subsection{Influence of heated length}

The numerical solutions of $q_{\text {inc }}$ for the heated length, $L$, of 49,99 and $149 \mathrm{~mm}$ are shown in Fig. 9 with the circle, triangle and rectangle symbols. The $q_{\text {inc }}$ values with and without the transition to film boiling are shown as the solid and open symbols, respectively. The $q_{\mathrm{cr} \text {,inc }}$ value is around $14 \mathrm{MW} / \mathrm{m}^{2}$ at the $L / d$ of 4.9 . They become lower with an increase in the $L / d$ and finally arrive at the value of about $12 \mathrm{MW} / \mathrm{m}^{2}$ at $L / d$ of 14.9 . The $q_{\mathrm{cr} \text {,inc }}$ value becomes $14.3 \%$ lower with an increase in $L / d$ from 4.9 to 14.9 . The critical heat fluxes, $q_{\mathrm{cr}, \mathrm{sub}}$, for uniformly heated tube are also shown in this figure for comparison. Furthermore, the values calculated from the CHF correlation against inlet subcooling mentioned below, Eq. (13), are shown as a broken line. The $q_{\mathrm{cr} \text { sub }}$ data are in good agreement with this correlation. The $q_{\mathrm{cr} \text {,inc }}$ values show nearly the same trend of dependence of $q$ on $L / d$ as $q_{\mathrm{cr}, \mathrm{sub}}$, although they are almost $38 \%$ lower than the latter. Based on these data under the subcooled condition, it is supposed that the liquid subcooling and the bubble boundary layer on the heated surface become little by little lower and thicker along the heated length of the test tube at the same inlet liquid subcooling, $\Delta T_{\text {sub,in }}$, condition for the wide $L / d$ range.

We derived the CHF correlation against inlet subcooling for wide $L / d$ range $(4.08<L / d<74.85)$ as follows 


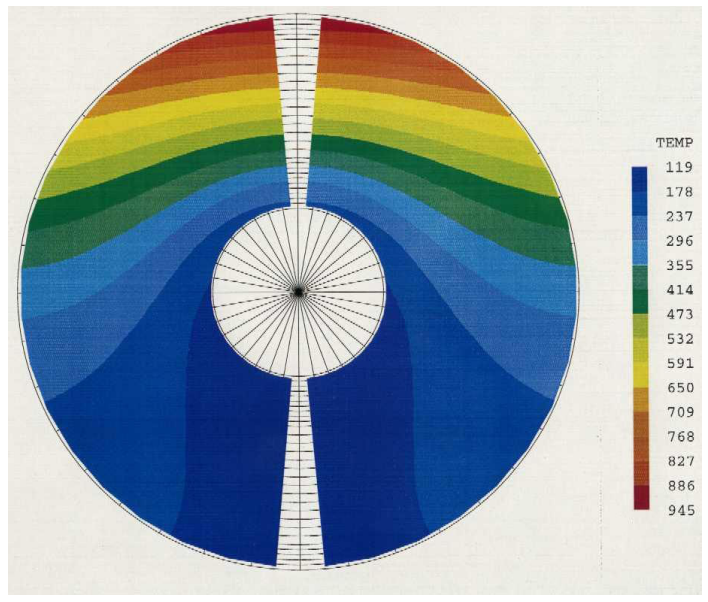

$\mathrm{q}_{\text {inc }}=11 \mathrm{MW} / \mathrm{m}^{2}$ (After $12 \mathrm{sec}$ of heating)

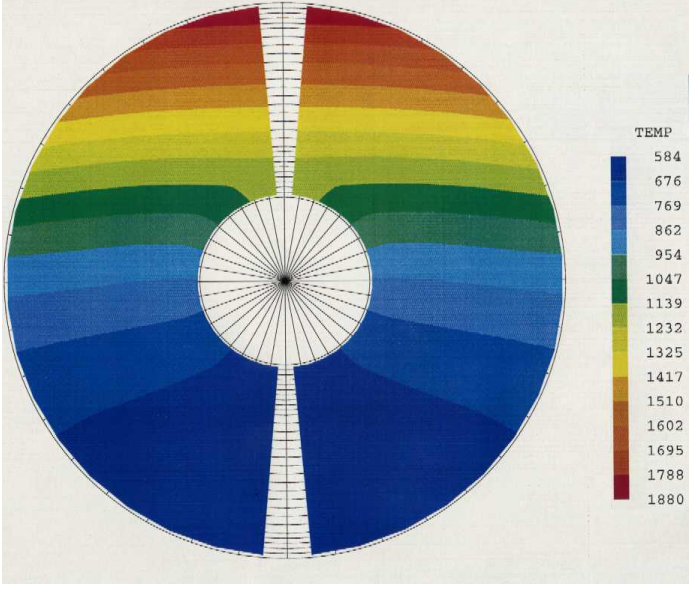

$\mathrm{q}_{\text {inc }}=12 \mathrm{MW} / \mathrm{m}^{2}$ (After $8 \mathrm{sec}$ of heating)

Fig. 8 Contour of cross-section temperature.

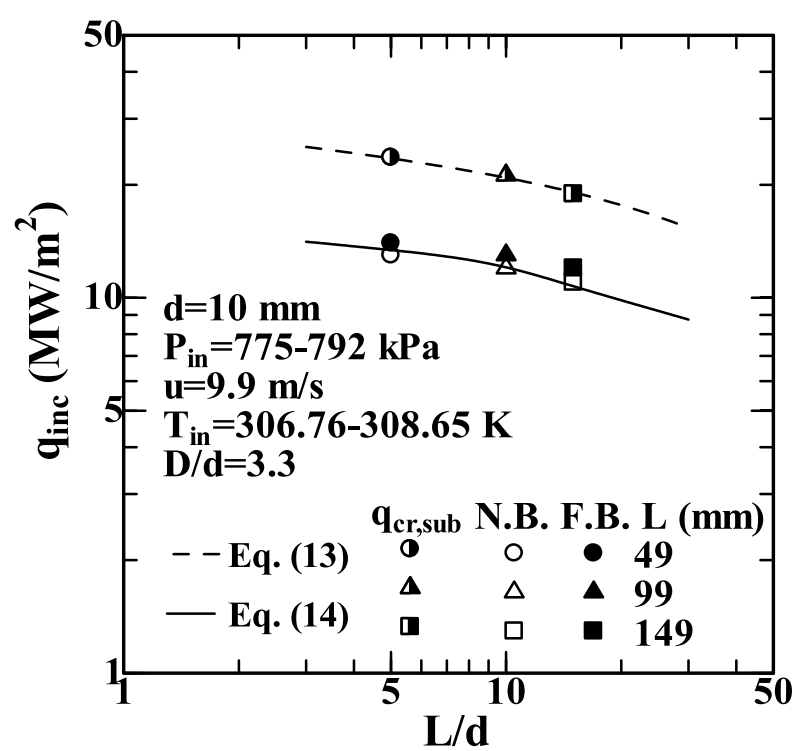

Fig. 9 Relationship between $q_{\text {inc }}$ and $L / d$ for $D / d=3.3$.

based on the effects of $L / d$ clarified in the CHF experiment $[12,13,16]$.

$$
\begin{aligned}
\text { Bo }= & C_{1}\left\{\frac{d}{\sqrt{\sigma /\left[g\left(\rho_{1}-\rho_{\mathrm{g}}\right)\right]}}\right\}^{-0.1} W e^{-0.3}\left(\frac{L}{d}\right)^{-0.1} \\
& \times \exp \left\{-\frac{(L / d)}{C_{2} R e^{0.4}}\right\} S c^{* C_{3}}
\end{aligned}
$$$$
\text { for inlet subcooling }\left(\Delta T_{\text {sub,in }} \geq 40 \mathrm{~K}\right) \text {, }
$$

where $C_{1}=0.082, C_{2}=0.53$ and $C_{3}=0.7$ for $L / d \leq$ around 40, and $C_{1}=0.092, C_{2}=0.85$ and $C_{3}=0.9$ for $L / d>$ around 40. $B o, R e, S c^{*}$ and $W e$ are boiling number, $\left(=q_{\mathrm{cr}} /\left(G h_{\mathrm{fg}}\right)\right)$, Reynolds number, $\left(=G d / \mu_{1}\right)$, non-dimensional inlet subcooling, $\left(=c_{\mathrm{pl}} \Delta T_{\text {sub,in }} / h_{\mathrm{fg}}\right)$ and Weber number, $\left(=G^{2} d /\left(\rho_{1} \sigma\right)\right)$, respectively. Saturated thermo-physical properties were evaluated at the outlet pressure.
This correlation can describe not only these CHF data for $P_{\text {in }}$ of around $800 \mathrm{kPa}$ but also the authors' published CHFs data (1805 points) for the wide ranges of $P_{\text {in }}=159 \mathrm{kPa}$ to $1 \mathrm{MPa}, d=2$ to $12 \mathrm{~mm}, L=21.5$ to $149.7 \mathrm{~mm}, \Delta T_{\text {sub,in }}=10$ to $151 \mathrm{~K}$ and $u=4.0$ to $13.3 \mathrm{~m} / \mathrm{s}$ within $15 \%$ difference for $40 \mathrm{~K} \leq \Delta T_{\text {sub,in }} \leq 151 \mathrm{~K}$.

\subsection{Influence of carbon armor thickness}

The divertor for the outer diameter, $D$, of $26 \mathrm{~mm}$ is numerically analyzed to clarify the influence of the thickness on the incident critical heat flux. The numerical solutions of $q_{\text {inc }}$ with $L=49,99$ and $149 \mathrm{~mm}$ are shown in Fig. 10 with the circle, triangle and rectangle symbols, respectively. The numerical solutions of $q_{\text {inc }}$ for $D=33 \mathrm{~mm}$ are also plotted in this figure for comparison. The $q_{\mathrm{cr} \text {,inc }}$ value for $L=149 \mathrm{~mm}$ as a typical example is around $12 \mathrm{MW} / \mathrm{m}^{2}$ at the $D / d$ of 3.3. They become larger with a decrease in the $D / d$ and arrive at the value of about $13 \mathrm{MW} / \mathrm{m}^{2}$ at $D / d$ of 2.6. The $q_{\text {crinc }}$ value becomes $8.3 \%$ larger with a decrease in $D / d$ from 3.3 to 2.6. It is supposed that the incident critical heat flux becomes higher for smaller $D / d$ value because the heat induced by collecting on the carbon armor upper surface with the outer diameter, $D$, and transfering to the cooling tube with $10 \mathrm{~mm}$ inner diameter becomes smaller for smaller $D / d$ value under the same incident heat flux condition.

\subsection{Influence of divertor shape}

Figure 11 shows the influence of the divertor shape on the incident critical heat flux. The numerical solutions of $q_{\text {inc }}$ for the Mono-block type divertor with $L=149 \mathrm{~mm}$ are plotted on the $q_{\text {inc }}$ vs. $D / d$ graph as open and solid triangles. Those for the Flat-plate type one are shown versus $w / d$ as open and solid circles in this figure for comparison $[9,10]$. The $q_{\mathrm{cr} \text {,inc }}$ value for the Flat-plate type one is around $16 \mathrm{MW} / \mathrm{m}^{2}$ at the $w / d$ of 1.6 . They become lower with an increase in the $w / d$ and finally arrive at the value 


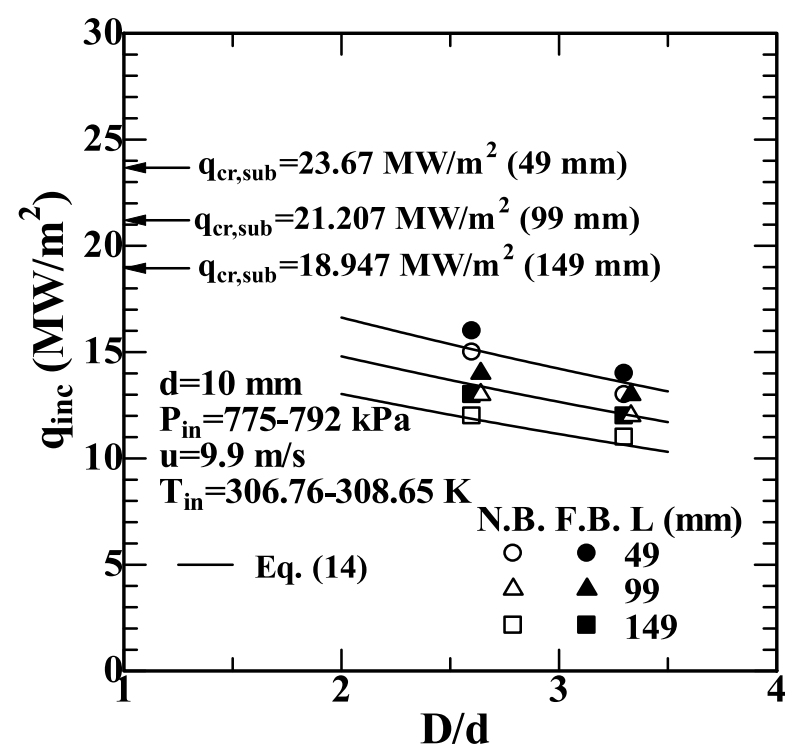

Fig. 10 Relationship between $q_{\text {inc }}$ and $D / d$ for $L=49,99$ and $149 \mathrm{~mm}$.

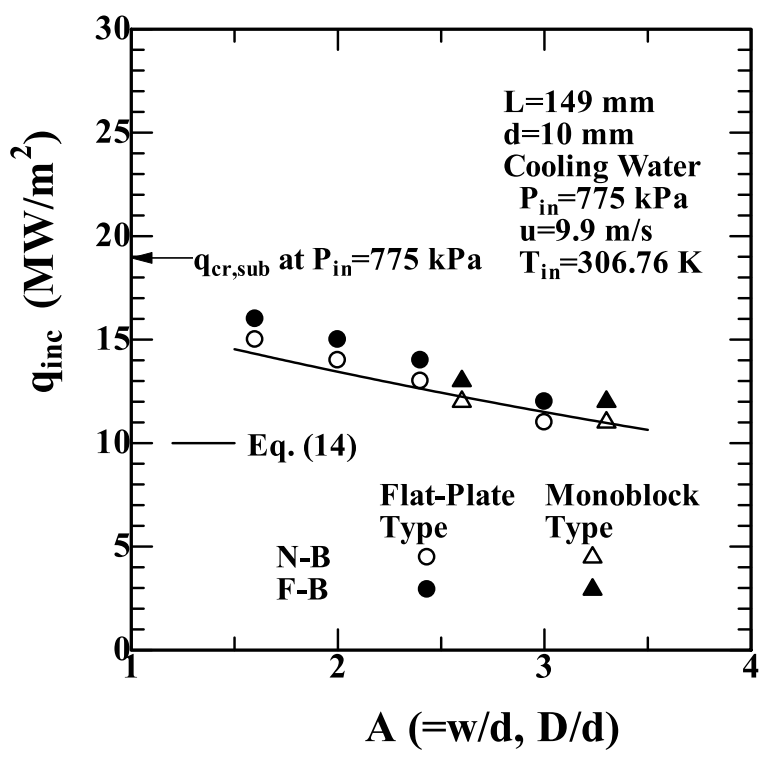

Fig. 11 Relationship between $q_{\text {inc }}$ and $A(=D / d, w / d)$ for the Mono-block type and Flat-plate type divertors.

of about $12 \mathrm{MW} / \mathrm{m}^{2}$ at $w / d$ of 3 . The $q_{\mathrm{cr} \text {,inc values become }}$ almost $4 \mathrm{MW} / \mathrm{m}^{2}$ lower with an increase in the $w / d$ from 1.6 to 3 . These $q_{\text {crinc }}$ values for the Mono-block type and Flat-plate type divertors are approximately expressed by the single curve on this figure with no influence of the divertor shape on the incident critical heat flux.

\subsection{Comparison with uniform heating data}

The ratios of the calculated $q_{\text {inc }}$ for the Mono-block type divertor and the Flat-plate type one with the cooling tube diameter of $10 \mathrm{~mm}$ at the pressures of $594 \mathrm{kPa}$ to $1 \mathrm{MPa}$ to the experimental data of $q_{\mathrm{cr}, \text { sub }}$ with the SUS304

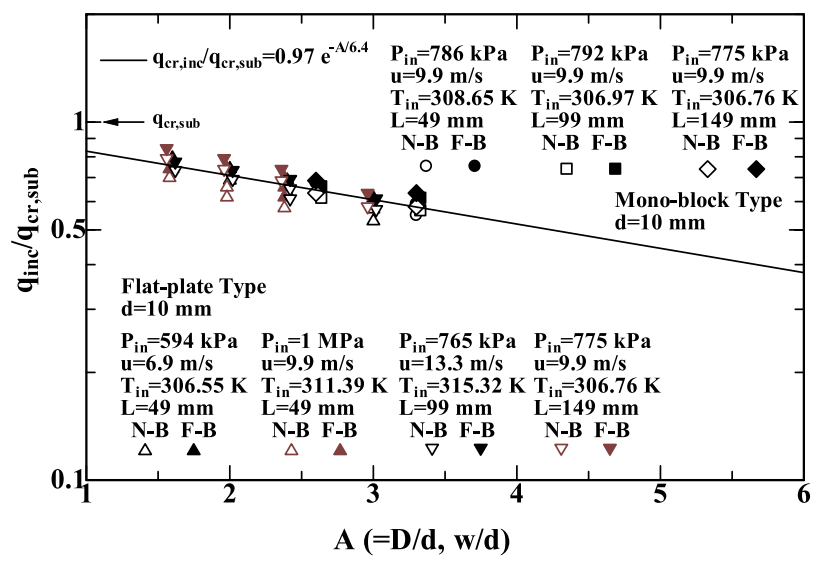

Fig. 12 Relationship between $q_{\text {inc }} / q_{\text {cr,sub }}$ and $A(=D / d, w / d)$ for the Mono-block type and Flat-plate type divertors.

tube of $9 \mathrm{~mm}$ inner diameter at the same pressure condition, $q_{\text {inc }} / q_{\text {cr,sub }}$, are shown vs $A(=D / d$ or $w / d)$ in Fig. 12 . The calculated values of the $q_{\text {crinc }}$ for the heated length of 49 to $149 \mathrm{~mm}$ with the flow velocity of 6.9 to $13.3 \mathrm{~m} / \mathrm{s}$ at the inlet pressure of $594 \mathrm{kPa}$ to $1 \mathrm{MPa}$ are approximately expressed by the following correlation:

$$
\frac{q_{\text {cr,inc }}}{q_{\text {cr,sub }}}=0.97 \mathrm{e}^{-A / 6.4}
$$

where $A=D / d$ for Mono-block type divertor and $A=w / d$ for Flat-plate type one.

The curve derived from this correlation is independent of the divertor shape, the flow velocity and the inlet pressure for the entire calculated range. On the other hand, the $q_{\mathrm{cr}, \text { sub }}$ value in Eq. (14) for $\Delta T_{\text {sub,in }}$ higher than around $40 \mathrm{~K}$ is given by Eq. (13). The $q_{\mathrm{cr} \text {,inc }}$ value for higher pressures can be predicted by using Eqs. (13) and (14). The $q_{\text {crinc }}$ value thus derived for the inlet pressures of $0.5,1$ and $2 \mathrm{MPa}$ at the flow velocity of $10 \mathrm{~m} / \mathrm{s}$ with the inlet liquid temperature of $308.15 \mathrm{~K}$ are shown in Fig. 13 as a curve for each value of the pressure. The $q_{\text {cr,inc }}$ value for $L=50 \mathrm{~mm}$ becomes higher than $20 \mathrm{MW} / \mathrm{m}^{2}$ with the decrease in the $A$ smaller than 2 for the pressure of $2 \mathrm{MPa}$. Those for $L=100$ and $150 \mathrm{~mm}$ becomes higher than $15 \mathrm{MW} / \mathrm{m}^{2}$ with the decrease in the $A$ smaller than 3.3 and 2.6 for the pressure of $2 \mathrm{MPa}$, respectively.

It is considered that the incident critical heat flux, $q_{\mathrm{cr}, \text { inc }}$, for the divertor will be larger than the value derived from Eqs. (13) and (14). Because the divertor is made of copper tube or copper block whose thermal conductivity is very high, and so the difference between the inlet and outlet temperatures of the divertor will become smaller than that of the experimental data by using the thin SUS304 tube. It is assumed based on this fact that Eq. (14) will give the lower limit for the ratio of the one side heating data to the uniform heating data. 


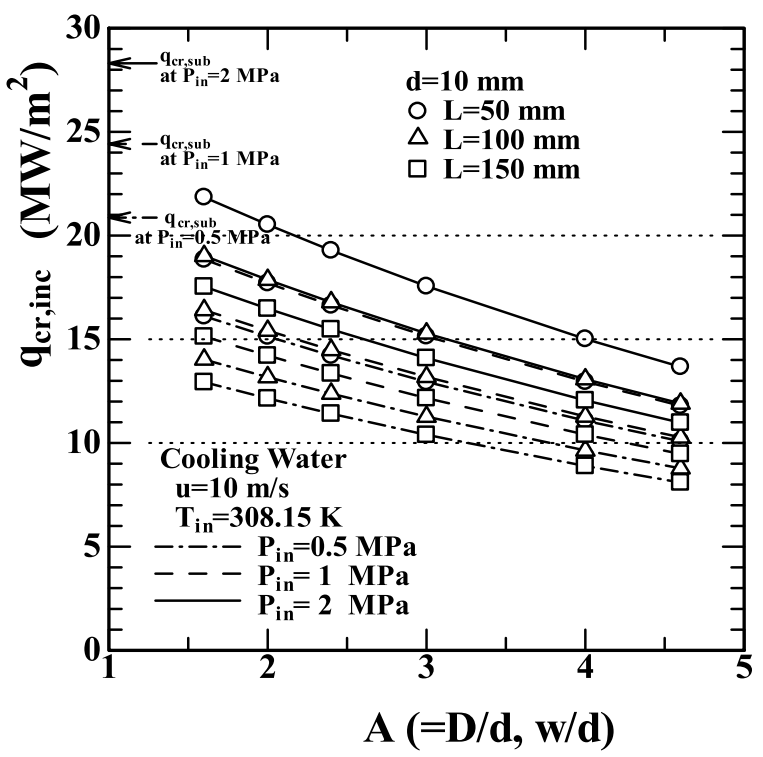

Fig. 13 Relationship between $q_{\mathrm{cr}, \text { inc }}$ and $A(=D / d, w / d)$ at $P_{\text {in }}=0.5,1$ and $2 \mathrm{MPa}$.

\section{Conclusions}

The subcooled flow boiling critical heat fluxes (CHFs) and the heat transfer coefficients (HTCs) for $L=49,99$ and $149 \mathrm{~mm}$ with 9-mm inner diameter were applied to thermal analysis of the Mono-block type divertor of LHD. Incident CHFs, $q_{\mathrm{cr}, \text { inc }}$, for the divertor with the cooling tube diameter, $d$, of $10 \mathrm{~mm}$ and the carbon armor outer diameter, $D$, of 26 and $33 \mathrm{~mm}$ were numerically analyzed.

The $q_{\mathrm{cr}, \mathrm{inc}}$ values become $14.3 \%$ lower with an increase in $L / d$ from 4.9 to 14.9 . They show nearly the same trend of dependence of $q_{\mathrm{cr} \text {,sub }}$ on $L / d$, although they are almost $38 \%$ lower than the values of $q_{\mathrm{cr}, \mathrm{sub}}$.

The $q_{\text {cr,inc }}$ values become almost $8.3 \%$ larger with a decrease in $D / d$ from 3.3 to 2.6.

The $q_{\text {cr,inc }}$ values were also compared with those for the Flat-plate type divertor with the cooling tube diameter $d=10 \mathrm{~mm}$ and the divertor width, $w$, ranging from 16 to $30 \mathrm{~mm}$. These $q_{\mathrm{cr} \text {,inc }}$ values for the Mono-block type and Flat-plate type divertors are approximately expressed by the single curve with no influence of the divertor shape on the incident critical heat flux.

The ratio of the one-side heating CHF data, $q_{\mathrm{cr} \text {,inc }}$, to the uniform heating CHF data, $q_{\mathrm{cr}, \mathrm{sub}}$, can be represented as the simple equation based on the numerical solutions.

The values of the $q_{\mathrm{cr} \text {,inc }}$ for the tube lengths of 50, 100 and $150 \mathrm{~mm}$ were estimated with various $D / d$ and $w / d$ at higher pressures.

\section{Acknowledgments}

This research was performed as a LHD joint research project of NIFS (National Institute for Fusion Science), Japan, L2-22, 2001-2003 and was partially supported by the Japan Society for the Promotion of Science, Grant in Aid for Scientific Research (C), 15560180, 2003 and 2004.

\section{Appendix}

A.1 Numerical analysis of the Flat-plate type divertor

The unsteady two dimensional heat conduction equation in boundary fitted coordinate as shown in Fig. A1 is described as follows:

$$
\begin{aligned}
& \frac{\partial}{\partial t}(\rho c T)=\frac{\partial}{\partial x}\left(\lambda \frac{\partial T}{\partial x}\right)+\frac{\partial}{\partial y}\left(\lambda \frac{\partial T}{\partial y}\right) \\
& \text { for } 0 \leq x \leq w / 2,0 \leq y \leq 0.035 .
\end{aligned}
$$

The numerical solution is performed within $0 \leq x \leq w / 2$ as the symmetrical problem. The boundary conditions are expressed in the following forms:

$$
\begin{array}{ll}
\frac{\partial T}{\partial x}=0 \quad \text { at } x=0, \\
\frac{\partial T}{\partial x}=0 \quad \text { at } x=w / 2, \\
\frac{\partial T}{\partial y}=0 \quad \text { at } y=0, \\
q=q_{\text {inc }} \quad \text { at } y=0.035, \\
q=-q_{\theta} \quad \text { at } x=\sqrt{\frac{d^{2}}{4}-(y-0.017)^{2},}
\end{array}
$$

where the divertor width, $w$, and the cooling tube diameter, $d$, are in (m) and the incident heat flux, $q_{\text {inc }}$, and the surface heat flux, $q_{\theta}$, of the cooling tube are in $\left(\mathrm{W} / \mathrm{m}^{2}\right)$. All calculations were made by using the PHOENICS code [23].

\section{A.2 Comparisons of our numerical solution with other worker's experimental data}

The mock-up experiment has been performed by Kubota et al. [24, 25] at the National Institute for Fusion Science (NIFS). This is the high heat flux heat removal experiment on the mock-up divertor plate heated by electron beam facility. The cross-sectional view of this divertor-plate is shown in Fig. A2. The hatched area on the upper surface of the divertor shown in figure is

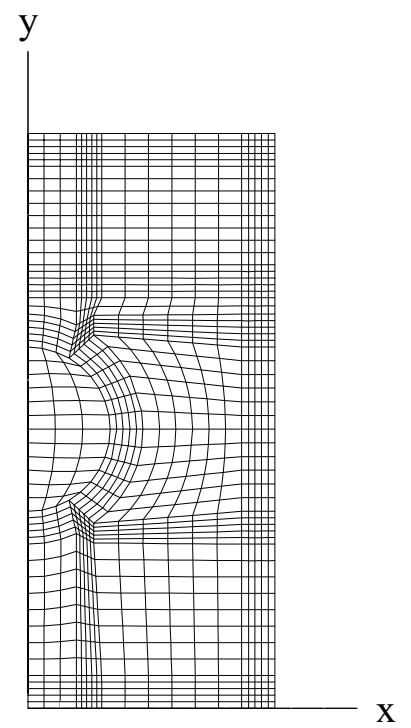

Fig. A1 Boundary fitted coordinates of Flat-plate type divertor. 
heated with the heat flux of $11.6 \mathrm{MW} / \mathrm{m}^{2}$. The incident heat flux, $q_{\text {inc }}$, within the heated length is equivalent to $10.826 \mathrm{MW} / \mathrm{m}^{2}$. The cooling water for $P_{\mathrm{in}}=500 \mathrm{kPa}$, $u=7 \mathrm{~m} / \mathrm{s}$ and $T_{\text {in }}=303.15 \mathrm{~K}$ is circulated through the divertor. The mock-up experimental results of time variations are shown in Fig. A3. The $T_{\text {wall }}$ is measured by a pyro-meter, and $T_{\mathrm{CX}}$ and $T_{\mathrm{Cu}}$ by thermocouples. These experimental data are numerically analyzed by the CFD code developed in this work. Figure A4 shows the numerically obtained time variations in the surface temperature, $T_{\text {wall }}$, the inner temperature of the carbon tile, $T_{\mathrm{cx}}$, and the inner temperature of the copper block, $T_{\mathrm{cu}}$, for $q_{\text {inc }}=10.8 \mathrm{MW} / \mathrm{m}^{2}$ with the divertor of $30 \mathrm{~mm}$ wide and the cooling tube diameter, $d$, of $10 \mathrm{~mm}$, which is cooled with highly subcooled and pressurized water for the inlet liquid temperature, $T_{\text {in }}$, of $306.55 \mathrm{~K}$ at the inlet pressure, $P_{\text {in }}$, of $594 \mathrm{kPa}$ with the flow velocity, $u$, of $6.9 \mathrm{~m} / \mathrm{s}$. The

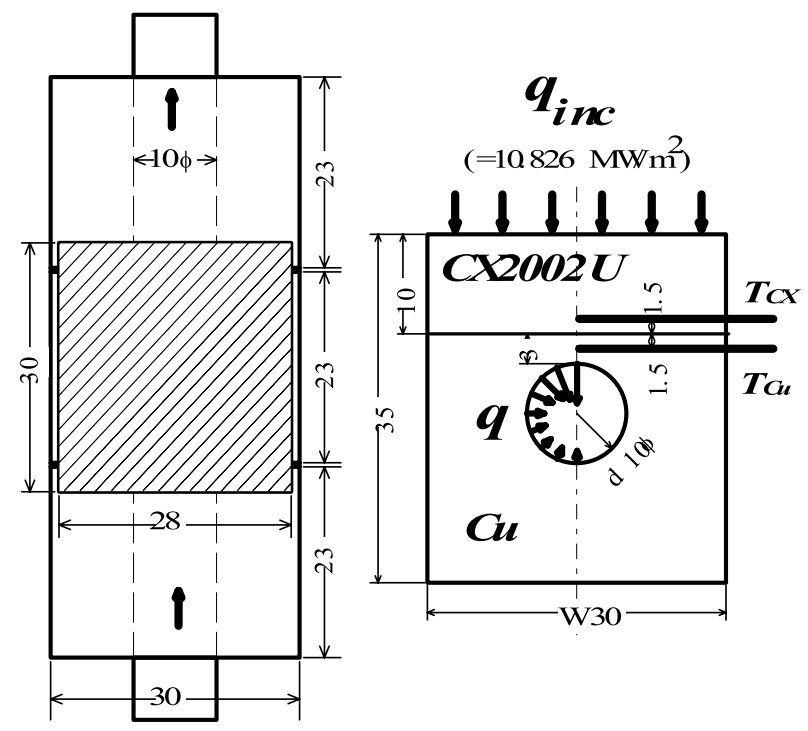

Fig. A2 Flat-plate type divertor used by the heat load test (Kubota et al. $[24,25])$.

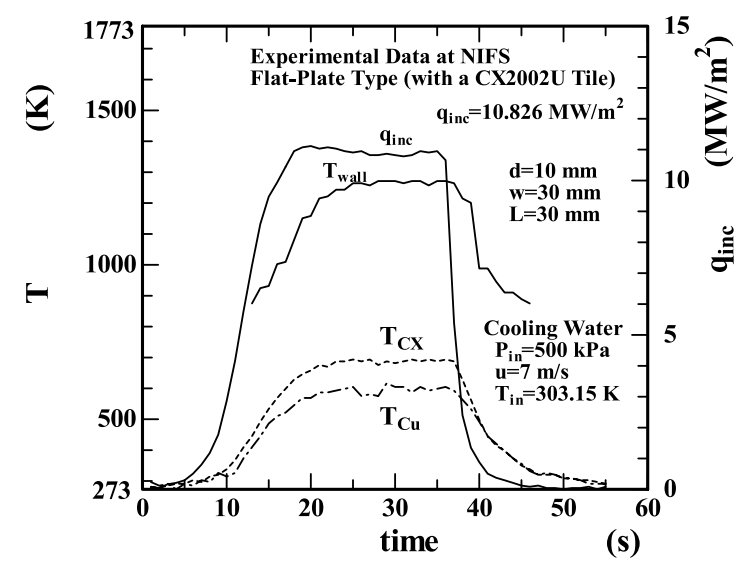

Fig. A3 Time variations in $T_{\text {wall }}, T_{\mathrm{CX}}$ and $T_{\mathrm{Cu}}$ for $q_{\mathrm{inc}}=10.8$ $\mathrm{MW} / \mathrm{m}^{2}$ in the heat load test (Kubota et al. $[24,25]$ ). experimental data in Fig. A3 are also shown in the figure for comparison. From the comparison of the numerical results with the mock-up results, the $T_{\text {wall }}, T_{\mathrm{CX}}$ and $T_{\mathrm{Cu}}$ in the numerical results and those in the mock-up results at maximum values are approximately same, respectively, although their increasing rates for the experiment are a little smaller than those for the numerical solution. This fact verified that numerical analyses are reliable. It is assumed that the incident heat flux of the mock-up experiment might be just below the maximum incident heat flux.

Figure A5 shows the comparison between Divavin et al.'s one-side-heating CHF data [4] without porous coating for $d=6 \mathrm{~mm}, w=13 \mathrm{~mm}, L=60 \mathrm{~mm}, \Delta T_{\text {sub,out }}=160 \mathrm{~K}$ and $P_{\text {in }}=2 \mathrm{MPa}$. These incident critical heat flux, $q_{\mathrm{cr}, \text { inc }}$, are numerically solved by the CFD code developed in this work. And the $q_{\text {cr,inc }}$ values are also predicted by the CHF correlation against inlet subcooling, Eq. (13), the $q_{\text {cr,inc }}$ correlation, Eq. (14) and the energy balance equation for the test

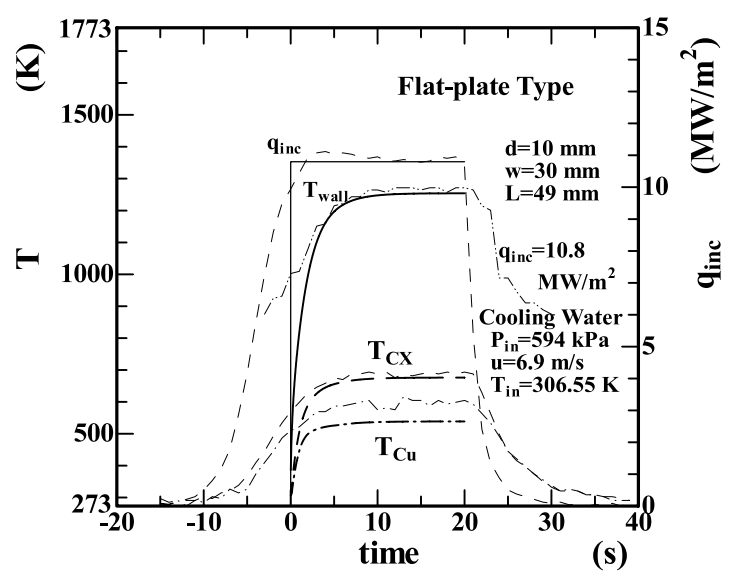

Fig. A4 Comparison of Kubota et al. data with the numerical solution.

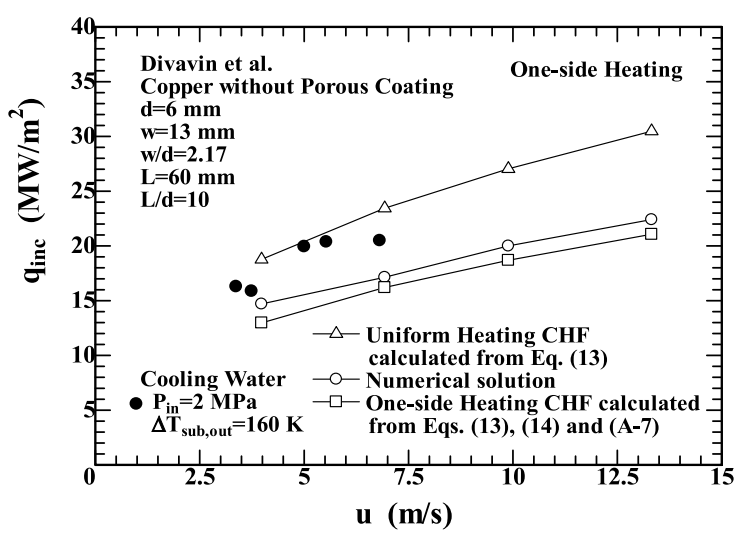

Fig. A5 Comparison of Divavin et al. data with the values calculated from Eqs. (13), (14) and (A7) (Divavin et al. [4]). 
tube given as

$$
\Delta T_{\text {sub,out }}=T_{\text {sat,out }}-\left(T_{\text {out }}\right)_{\mathrm{cal}}=T_{\text {sat,out }}-\left(T_{\mathrm{in}}+\frac{4 L q_{\mathrm{cr}, \mathrm{sub}}}{u c_{\mathrm{pl}} \rho_{\mathrm{l}} d}\right),
$$

where $\Delta T_{\text {sub,out }}, T_{\text {sat,out }}$ and $\left(T_{\text {out }}\right)_{\text {cal }}$ are outlet liquid subcooling $(\mathrm{K})$, outlet saturation temperature $(\mathrm{K})$ and calculated outlet liquid temperature $(\mathrm{K})$. Thermo-physical properties were evaluated at the temperature of $\left\{T_{\text {in }}+\right.$ $\left.\left(T_{\text {out }}\right)_{\text {cal }}\right\} / 2$. The average values of their experimental data show nearly same trends of dependence on $u$. And furthermore, those are also within $25 \%$ of the values obtained from the values calculated from Eqs. (13), (14) and (A7) and the numerical solutions.

[1] W.R. Gambill, R.D. Bundy and R.W. Wansbrough, Chem. Eng. Prog. Symp. Series 57, 127 (1961).

[2] S.L. Milora, S.K. Combs and C.A. Foster, Nucl. Eng. Des./Fusion 3, 301 (1986).

[3] H. Nariai, A. Ishikawa and F. Inasaka, Proc. NURETH-6, (1993) p. 715.

[4] V.A. Divavin, S.A. Grigoriev and V.N. Tanchuk, Proc. ASME Heat Transfer Division, HTD-Vol. 317-1, IMECE (1995) pp. 143-148.

[5] J. Boscary, M. Araki and M. Akiba, JAERI-Research 97053 (Japan Atomic Energy Research Institute, 1997).

[6] R.D. Boyd, A. Ekhlassi, P. Cofie and H. Zhang, Int. J. Heat Mass Transf. 47, 2183 (2004).

[7] K. Hata, K. Fukuda, M. Shiotsu, A. Sakurai, N. Noda, O. Motojima and A. Iiyoshi, Proc. 6th International Conference on Nuclear Engineering, ICONE-6362 (1998) pp. 116.

[8] K. Hata, K. Fukuda, M. Shiotsu and A. Sakurai, 9th Int. Topical Meeting on Nuclear Reactor Thermal Hydraulics (1999) pp. 1-20.

[9] G. Sato, K. Hata, M. Shiotsu and N. Noda, Proc. 8th Int.
Conference on Nuclear Engineering, ICONE-8126 (2000) pp.1-12.

[10] K. Hata, T. Sato and M. Shiotsu, Proc. 9th Int. Conference on Nuclear Engineering, ICONE-9569 (2001) pp. 1-12.

[11] K. Hata, T. Sato, T. Tanimoto, M. Shiotsu and N. Noda, Proc. 10th Int. Conference on Nuclear Engineering, ICONE10-22324 (2002) pp. 1-10.

[12] K. Hata, T. Tanimoto, H. Komori, M. Shiotsu and N. Noda, Proc. 11th Int. Conference on Nuclear Engineering, ICONE11-36116 (2003) pp. 1-10.

[13] K. Hata, H. Komori, M. Shiotsu and N. Noda, Proc. 10th Int. Topical Meeting on Nuclear Reactor Thermal Hydraulics, NURETH10-C00207 (2003) pp. 1-13.

[14] K. Hata, H. Komori, M. Shiotsu and N. Noda, Proc. 12th Int. Conference on Nuclear Engineering, ICONE12-49194 (2004) pp. 1-10.

[15] K. Hata, M. Shiotsu and N. Noda, J. Heat Transf., Trans. ASME, Series C, 126, 312 (2004).

[16] K. Hata, H. Komori, M. Shiotsu and N. Noda, JSME International Journal, Series B, 47, 306 (2004).

[17] W. Nusselt, Forsch. Geb. Ingenieurwes. 2, 309 (1931).

[18] M. Shiotsu and K. Hama, Proc. NURETH-8, Vol. 2 (1997) pp. 679-690.

[19] M. Shiotsu and K. Hama, Nuc. Eng. Des. 200, 23 (2000).

[20] A. Sakurai, M. Shiotsu and K. Hata, Heat and Fluid Flow in Water Reactor Safety, C199/77, (The Institute of Mechanical Engineers, London, 1977) pp.55-62.

[21] A. Sakurai, M. Shiotsu and K. Hata, Multiphase Transport, Fundamentals, Reactor Safety, Applications, Vol. II, (Hemisphere Pub. Corp., Washington D.C., 1980), pp.727747.

[22] A. Sakurai, M. Shiotsu and K. Hata, Experimental Thermal and Fluid Science 3, 450 (1990).

[23] D.B. Spalding, The PHOENICS Beginner's Guide (CHAM, UK, 1991).

[24] Y. Kubota, N. Noda, A. Sagara, A. Komori, N. Inoue, K. Akaishi, H. Suzuki, N. Ohyabu and O. Motojima, Proc. ASME Heat Transfer Division, HTD-Vol. 317-1, IMECE (1995) pp.159-163.

[25] Y. Kubota, private communication, December 28, (1998). 